\title{
Can we reduce failed instrumental delivery?
}

\author{
Dasanayaka DLW ${ }^{1}$, Sidique $\mathrm{A}^{2}$, Hooker $\mathbf{J}^{2}$ \\ ${ }^{\prime}$ Department of Obstetrics \& Gynaecology, Faculty of Medicine, University of Ruhuna, Galle, Sri Lanka \\ ${ }^{2}$ Department of Obstetrics, St. Richard's Hospital, Western Sussex Hospitals NHS Trust, Chichester, UK
}

Correspondence: Dr. Lanka Dasanayake

e-mail:lanka.dasanayake@yahoo.com

\begin{abstract}
Background: Second stage caesarean sections following failed instrumental delivery are in rising trend. Maternal and neonatal risks are significantly high following failed instrumental deliveries. Identification of contributing factors is important to modify the success rate of instrumental delivery. The objective of this study was to identify the potential contributing factors for failed instrumental delivery and to assess major maternal and neonatal morbidity associated with such deliveries.
\end{abstract}

Methods: This retrospective observational study was carried out in the Obstetric Department, St. Richard's Hospital, United Kingdom from $01^{\text {st }}$ December 2011 to $30^{\text {th }}$ April 2012. Data collection was carried out using proforma. Contributing factors were predetermined.

Results: Total number of births during particular period was 2825 . There were 44 failed instrumental deliveries out of 275 trials. The overall rate of failed instrumental delivery was 16\%. In 54.5\% (24 of 44) of cases, consultant was not present physically at the time of delivery. Position of the head was not properly determined in $32 \%$ (14 of 44$)$ of cases. Eighteen (41\%) deliveries had been carried out by junior doctors $\left(\leq \mathrm{ST}_{3}\right)$. Thirty one $(70 \%)$ of patients had attempted ventouse deliveries. Twenty five $(58 \%)$ women had primary postpartum haemorrhage and $21 \%(9)$ of newborn babies had cord $\mathrm{pH} \leq 7.2$.

Conclusion: Significant number of failed instrumental deliveries happened due to the lack of consultant involvement, involvement of junior medical staff, failure to determine position of head and more frequent use of ventouse rather than forceps. There were significant major neonatal and maternal morbidities. We recommend structured junior staff training on instrumental delivery with assessment of competencies. Consultant involvement and appropriate use of instruments are important to optimize success rate of instrumental delivery.

Key words: Failed instrumental delivery, Second stage caesarean section, Operative vaginal delivery

\section{Introduction}

Safe and effective management of second stage of labour presents a clinical challenge for labouring women and practitioners in obstetric care. There has been a disproportionate rise in caesarean sections performed in second stage of labour, specially following failed instrumental delivery in the last few years (1). Maternal and neonatal risks are significantly high after failed instrumental deliveries (2). Although second stage caesarean section is appropriate in some instances, many could be prevented by necessary attendance of senior obstetric staff, comprehensive assessment of suitability of instrumental delivery and the use of appropriate instrument (3).

Despite much discussion on the increase in elective caesarean section rate over the past twenty years, little attention has been paid to the rise in second stage caesarean section rate (3). This study focused on factors which contribute to second stage 
caesarean section rate following failed instrumental delivery. Our main objective was to identify potential contributing factors for failed instrumental delivery. Also we wished to determine major maternal and neonatal morbidity associated with such deliveries.

\section{Methods}

This study was carried out as a retrospective observational study in the Obstetric Department, St. Richard's Hospital, United Kingdom from $01^{\text {st }}$ December 2011 to $30^{\text {th }}$ April 2012. Ethical approval was obtained from the ethics and research committee of West Sussex NHS Trust. All eligible women were identified with the help of the Data Management Team of Women Health. All consecutive women delivered by caesarean section following failed trial of instrumental were recruited. Proforma was used to collect data from hospital notes. Potential contributing factors for failed instrumental delivery were predetermined.

\section{Results}

Total number of births was 2825. Number of caesarean sections performed was 887 . Forty four women underwent caesarean section after failed trial of instrumental delivery out of 275 attempted. The overall rate of failed instrumental delivery was $16 \%$.

Table 1: Demographic data

\begin{tabular}{lll}
\hline Category & \multicolumn{2}{l}{ Value } \\
\hline Mean age (range) & 29 year $\quad(19-39)$ \\
Mean BMI (range) & $26.4 \mathrm{kgm}^{-2}(20-37)$ \\
Parity $\left(\mathrm{P}_{0}\right)$ & $86 \%$ & \\
Period of gestation (range) & 40 weeks & $(36-42)$ \\
Birth weight (range) & $3.2 \mathrm{~kg} \quad(2.8-4.2)$ \\
\hline
\end{tabular}

Of the 44 failed instrumental deliveries, in 24 (53\%) cases, consultant was not present, physically, at the time of the delivery. However, all (44) cases has been informed to the relevant consultant.
Position of the head was not properly determined in $32 \%(14 / 44)$ women. Major two positions were DOP $(41 \%)$ and OT (19\%). Eighteen (42\%) deliveries has been carried out by junior staff $\left(\leq \mathrm{ST}_{3}\right)$ while 15 (35\%) deliveries has been done by consultants and the rest of deliveries (28\%) (11) by $\mathrm{SpR}>\mathrm{ST}_{3}$. Ventouse has been attempted in 31 (71\%) deliveries while $9(20 \%)$ were forceps deliveries and $4(9 \%)$ were sequential use of instruments. Twenty five (58\%) women had primary postpartum haemorrhage while 04 had uterine angle extensions. Nine (21\%) newborn babies had cord $\mathrm{pH} \leq 7.2$.

\section{Discussion}

Rate of failed instrumental deliveries in our study was $16 \%$, which is almost equal to the UK national average of $15 \%$ (4). Currently obstetric trainees perform most of trial of instrumental deliveries without consultant involvement. A recent UK study found that decisions made by consultant obstetric staff are important in determining whether a second stage caesarean section is the optimal method of delivery for women with delayed second stage of labour (5). However, in our study in majority of cases consultant was not present physically when the decision was made and almost half of deliveries were carried out by junior medical staff.

The Royal college of Obstetricians and Gynaecologists recommends the presence of consultant obstetrician whenever a caesarean section is performed in second stage of labour (1). Without enhancing junior doctor's experience the problem with second stage caesarean section after failed instrumental delivery will rise.

It is well known that failure rate with ventouse is more likely than forceps. In those births when instrumental delivery was attempted, an audit found failure rate of $35 \%$ for ventouse and $2 \%$ for forceps (1). In our study, in vast majority of deliveries the attempted method was ventouse.

Issues related to training of junior doctors are paramount important for safe and successful delivery. In addition to other prerequisites recommended by the RCOG, identification of position of the fetal head is vital for successful delivery (6). In our study in almost one third of cases, position of fetal head was not properly determined. 
Caesarean section in the second stage of labour after failed instrumental is a difficult procedure. The common maternal complications are postpartum haemorrhage, sepsis, uterine tears. Neonatal morbidity such as birth asphyxia, trauma and admission to neonatal unit are significantly high (2).

Our study clearly shows that failed instrumental deliveries are associated with lack of consultant direct supervision, failure of correct identification of the position of the fetal head, involvement of junior staff and the use of ventouse. There was a significant number of maternal and neonatal morbidity in caesarean section after failed instrumental delivery.

We would recommend the need of a physical involvement of consultant in delivery of failed trial of instruments. It is a timely requirement to develop and maintain junior staff skills for safe and effective instrumental delivery through structured training and assessment of competencies. Development of unit guidelines adapted from the RCOG Green Top Guidelines is necessary for uniform and evidence based practice. Timely auditing will ensure identification of deficiencies and reinforcement of those deficiencies.

\section{References}

1. Royal College of Obstetricians and Gynaecologists. Clinical effectiveness support unit. The national sentinel caesarean section audit report 2001. Available in www.rcog.org.uk

2. McKelvey A, Ashe R, McKenna D, Roberts R. Caesarean section in the second stage of labour: A retrospective review of obstetric setting and morbidity. J Obstet and Gynaecol 2010; 30(3): 264-7.

3. Spencer C, Murphy D, Bewley S. Caesarean delivery in the second stage of labour. British Medical Journal 2006; 333 : 613-4.

4. Maheswari S, Monica K, Shagaf B. Audit of trial of instrumental delivery. $9^{\text {th }}$ International scientific meeting of RCOG, Athens, Greece. $28^{\text {th }}-30^{\text {th }}$ September 2011.

5. Olah KS. Reversal of the decision for caesarean section in the second stage of labour on the basis of consultant vaginal assessment. JObst Gynaecol 2005; 25(2): 115-6.

6. Royal college of Obstetrician and Gynaecologist. Green-Top Guideline No. 26 (operative vaginal delivery). January 2011: RCOG London. Available in www.rcog.org.uk 